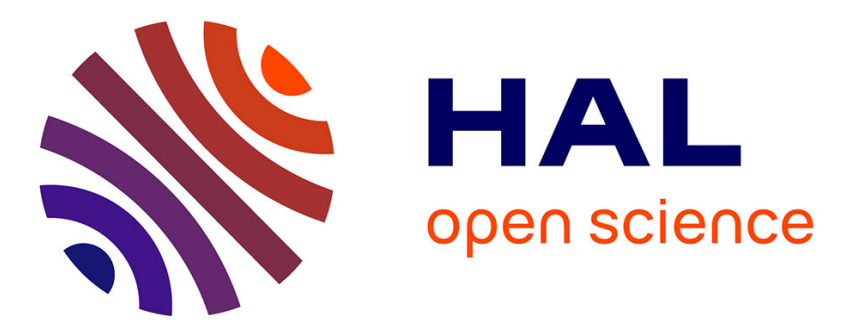

\title{
Radiation-induced Ostwald ripening in oxide dispersion strengthened ferritic steels irradiated at high ion dose
} M.-L. Lescoat, J. Ribis, Y. Chen, E.A. Marquis, E. Bordas, P. Trocellier, Y. Serruys, A. Gentils, O. Kaitasov, Y. de Carlan, et al.

\section{- To cite this version:}

M.-L. Lescoat, J. Ribis, Y. Chen, E.A. Marquis, E. Bordas, et al.. Radiation-induced Ostwald ripening in oxide dispersion strengthened ferritic steels irradiated at high ion dose. Acta Materialia, 2014, 78 (78), pp.328-340. 10.1016/j.actamat.2014.06.060 . in2p3-01059153

\section{HAL Id: in2p3-01059153 \\ https://hal.in2p3.fr/in2p3-01059153}

Submitted on 27 May 2020

HAL is a multi-disciplinary open access archive for the deposit and dissemination of scientific research documents, whether they are published or not. The documents may come from teaching and research institutions in France or abroad, or from public or private research centers.
L'archive ouverte pluridisciplinaire HAL, est destinée au dépôt et à la diffusion de documents scientifiques de niveau recherche, publiés ou non, émanant des établissements d'enseignement et de recherche français ou étrangers, des laboratoires publics ou privés. 


\title{
Radiation-induced Ostwald ripening in oxide dispersion strengthened ferritic steels irradiated at high ion dose
}

\author{
M.-L. Lescoat ${ }^{\text {a }}$, J. Ribis ${ }^{\text {a,*, }}$ Y. Chen ${ }^{\text {b }}$, E.A. Marquis ${ }^{b}$, E. Bordas ${ }^{\mathrm{c}}$, P. Trocellier ${ }^{\mathrm{c}}$, \\ Y. Serruys ${ }^{\text {c }}$, A. Gentils ${ }^{\mathrm{d}}$, O. Kaïtasov ${ }^{\mathrm{d}}$, Y. de Carlan ${ }^{\mathrm{a}}$, A. Legris ${ }^{\mathrm{e}}$ \\ ${ }^{\text {a } C E A, D E N, ~ S R M A, ~ F-91191 ~ G i f ~ s u r ~ Y v e t t e, ~ F r a n c e ~}$ \\ ${ }^{\mathrm{b}}$ Department of Materials Science and Engineering, University of Michigan, Ann Arbor, MI 48109-2136, USA \\ ${ }^{\mathrm{c}}$ CEA, DEN, Service de Recherches de Métallurgie Physique, Laboratoire JANNUS, F-91191 Gif sur Yvette, France \\ ${ }^{\mathrm{d}}$ CSNSM, CNRS/IN2P3, Univ Paris-Sud, Bât. 108, 91405 Orsay Cédex, France \\ e UMET, CNRS/UMR 8207, Bât. C6, Université Lille 1, 59655 Villeneuve d'Ascq, France
}

Received 14 February 2014; received in revised form 16 May 2014; accepted 26 June 2014

Available online 30 July 2014

\begin{abstract}
Oxide dispersion strengthened (ODS) ferritic steels are considered promising candidates as cladding tubes for Generation IV nuclear reactors. In such reactors, irradiation damage can reach more than $150 \mathrm{dpa}$ at temperatures ranging from 400 to $650{ }^{\circ} \mathrm{C}$. Thus nanoparticle stability has to be guaranteed in order to ensure that these materials possess excellent creep properties. Using Fe ions, ODS steels were irradiated at $500{ }^{\circ} \mathrm{C}$ up to $150 \mathrm{dpa}$. At this temperature the nano-oxide population evolution under irradiation is similar to that observed after annealing at high temperature. It consists of a slight increase in the particle size and a slight decrease in the density, which can be both explained by an Ostwald ripening mechanism. Conversely, irradiations performed at room temperature using Au ions lead to a complete dissolution of the oxide particles, in agreement with the estimation of ballistic vs. radiation enhanced diffusion effects.
\end{abstract}

(C) 2014 Acta Materialia Inc. Published by Elsevier Ltd. All rights reserved.

Keywords: ODS steels; Irradiation effect; Ostwald ripening; Phase stability; Atom-probe tomography

\section{Introduction}

In oxide dispersion strengthened (ODS) ferritic/ martensitic steels, the dispersion of nanosized oxide particles in the matrix confers very good creep strength at high temperatures. Therefore, these materials are promising candidates for fuel cladding in sodium-cooled fast reactors and for structural applications in fusion reactors. Thus, a research program dedicated to ODS materials has been engaged at CEA in collaboration with EDF and Areva [1-3].

\footnotetext{
* Corresponding author. Tel.: +3316908 85 09; fax: +33169087130. E-mail address: joel.ribis@cea.fr (J. Ribis).
}

In sodium-cooled fast reactors, severe irradiation and temperature conditions are expected. More specifically, the materials undergo irradiation damage of $>150 \mathrm{dpa}$ at temperatures ranging from 400 to $650^{\circ} \mathrm{C}$. As a consequence, it is very important to ensure the stability of the nanosized oxide particles under high-dose irradiation at high temperatures.

Many authors have studied the stability of nano-oxides in steels under neutron irradiation. While Yamashita et al. [4] reported a decrease in the nano-oxide density in MA957 alloy after irradiation at $500{ }^{\circ} \mathrm{C}$ up to $104 \mathrm{dpa}$, Gelles [5] reported no significant changes concerning nano-oxide distribution in this alloy at $480{ }^{\circ} \mathrm{C}$ for a higher dose level of $200 \mathrm{dpa}$. Ribis and Lozano-Perez [6-8] also found that nano-oxides were still present without any significant 
change after irradiation of up to $75 \mathrm{dpa}$ at $430{ }^{\circ} \mathrm{C}$ in MA957 alloy. Since the study of neutron-irradiated materials is challenging, many authors have resorted to ion irradiation, which offers more practical control over the range of doses and temperatures that can be reached. Some of these authors have shown that nano-oxides are stable under low damage ion irradiation $(0.7,1,5,10 \mathrm{dpa})$ at $300{ }^{\circ} \mathrm{C}[9]$ and $500{ }^{\circ} \mathrm{C}$ [10]. Other groups have shown that no significant changes in particle size were observed using transmission electron microscopy (TEM) for $20 \mathrm{dpa}$ at 200,500 and $700{ }^{\circ} \mathrm{C}$ [11], for $60 \mathrm{dpa}$ at $650{ }^{\circ} \mathrm{C}$ [12], and for $150 \mathrm{dpa}$ at $670{ }^{\circ} \mathrm{C}$ [13]. However, some authors observed a change in the nanoparticle population with a decrease in the average size after low ion dose irradiation (1 dpa) at $525^{\circ} \mathrm{C}$ [14]. Others reported structural changes such as amorphization with modified shapes of the nanooxides at $400{ }^{\circ} \mathrm{C}$ under $33 \mathrm{dpa}$ [15]. Using atom probe tomography (APT), Certain et al. [16] found complete dissolution of nanoparticles after irradiation at $-75^{\circ} \mathrm{C}$ up to $100 \mathrm{dpa}$ while a stable nanoparticle population was observed at $600{ }^{\circ} \mathrm{C}$, suggesting that radiation-enhanced diffusion allowed ejected atoms to reform nanoparticles. However, the inherent inhomogeneous spatial and size distribution of the particles in these ODS alloys [17] challenges the interpretation of such observations. To get around this problem, some authors have resorted to in situ TEM irradiation. Using this technique, Lescoat et al. [18] demonstrated that nanoparticles are apparently stable up to $45 \mathrm{dpa}$ at $500{ }^{\circ} \mathrm{C}$.

Overall, therefore, the literature reaches no definite conclusion concerning the nanoparticle stability under irradiation. At high temperatures $\left(500^{\circ} \mathrm{C}\right)$, the nanoparticle population mostly appears to be stable, while at low temperatures, where the thermal diffusion is weak, complete dissolution of the nanoparticles is observed. These results highlight the effect of competition between ballistic ejection and thermal diffusion on nanoparticle stability. To further investigate this phenomenon, the present work focuses on the evolution of the nano-oxide dispersion in a $\mathrm{Fe}-18 \mathrm{Cr}$ ferritic ODS alloy after high ion dose irradiations at high and room temperatures.

\section{Experimental}

The Fe18Cr1W0.3Ti $+0.6 \mathrm{Y}_{2} \mathrm{O}_{3}$ (wt.\%) ODS ferritic steel (referred to as " $\mathrm{Fe} 18 \mathrm{Cr}-\mathrm{Y}_{2} \mathrm{O}_{3}$ ") is one of the alloys developed at CEA/SRMA for nuclear applications [1]. Two pre-alloyed metal and oxide powders supplied by Aubert \& Duval (France) were mechanically alloyed in an attritor under hydrogen at Plansee AG (Austria). The material was then consolidated at CEA. A bar was hot extruded at $1100{ }^{\circ} \mathrm{C}$, hot rolled $20 \%$ at $650{ }^{\circ} \mathrm{C}$ and annealed for $1 \mathrm{~h}$ at $1050^{\circ} \mathrm{C}$. The chemical composition of the alloy is given in Table 1.

The material microstructures prior to and after irradiation were characterized by TEM at CEA and by APT at the
University of Michigan. TEM disks were punched from $60 \mu \mathrm{m}$ thick mechanically polished foils and electropolished using a $10 \%$ perchloric acid $/ 90 \%$ ethanol solution at $-10{ }^{\circ} \mathrm{C}$ in a Struers Tenupol thinning device. Conventional and high-resolution TEM (HRTEM) were performed using a JEOL 2010 (FEG) operating at $200 \mathrm{kV}$. APT specimens were prepared from non-irradiated and irradiated TEM thin foils using a standard lift-out method and annular ion beam milling on a FEI Nova SEM/FIB dual-beam microscope. APT analysis was performed on a CAMECA LEAP-4000X HR instrument operating in laser pulsing mode at a repetition rate of either 250 or $200 \mathrm{kHz}$ with laser pulse energies below $80 \mathrm{pJ}$ per pulse. The specimens were maintained at a temperature of $\sim 40 \mathrm{~K}$ and the evaporation rate was kept constant at 0.005 ions per pulse. APT data were reconstructed with IVAS 3.6.4 from CAMECA using a combination of an evaporation field of $33 \mathrm{~V} \mathrm{~nm}^{-1}$ and an image compression factor of 1.6 based on the shape of the oxide particles and grain boundaries from the reconstructed results. The maximum separation method was used in this study to define oxide particles embedded in the matrix [19]. The atomic and molecular species $\mathrm{Ti}$, $\mathrm{TiO}, \mathrm{Y}, \mathrm{YO}$ and $\mathrm{CrO}$, with separation distances smaller than a value $d_{\max }$, were selected to define the clusters. These species are called "core" species. The value for $d_{\max }$ was determined from the nearest-neighbor distribution for all the selected species, which exhibits two distinct peaks, one at small distances for the clusters and one for the dilute matrix with larger average distances between the species. The local minimum between the two peaks was selected as a $d_{\max }$ value. In addition, clusters smaller than a critical value of $\mathrm{N}_{\min }$ were considered as random clusters in the matrix solid solution and were removed from the analysis. The value of $\mathrm{N}_{\min }$ was determined by comparing computed random solid solutions of similar solute concentrations [20]. All atoms located within a distance of $L=d_{\max }$ from the core atoms are then added to the clusters. An erosion parameter, $d_{e}$, was used to remove the matrix atoms at the interface between clusters and matrix. This distance $\mathrm{d}_{\mathrm{e}}$ is set as the distance between $\mathrm{d}_{\max }$ and the first peak in the nearest-neighbor distribution.

Two irradiations using $500 \mathrm{keV} \mathrm{Fe}{ }^{+}$self-ions with a flux of $2.6-2.8 \times 10^{12}$ ions $\mathrm{cm}^{-2} \mathrm{~s}^{-1}$ were performed at the CEA-JANNuS-Saclay facility [21]. Specimens had thin-foil geometry, were maintained at a nominal temperature of $500{ }^{\circ} \mathrm{C}$, and were tilted by $15^{\circ}$ with respect to the incoming ion beamline. Irradiations using $4000 \mathrm{keV} \mathrm{Au}{ }^{2+}$ ions at a flux of $7.8 \times 10^{10}$ ions $\mathrm{cm}^{-2} \mathrm{~s}^{-1}$ were performed at room temperature at the CSNSM-JANNuS-Orsay facility [22].

A recent paper [23] recommends converting SRIM simulations [24] into dpa by calculating irradiation damage under the Kichin-Pease mode with $40 \mathrm{eV}$ displacement energy and $0 \mathrm{eV}$ lattice binding energy. From this calculation, the maximum irradiation dose reached within the first $150 \mathrm{~nm}$ are 74.4 and $150 \mathrm{dpa}$ for $500 \mathrm{keV}$ incident $\mathrm{Fe}^{+}$ions (Fig. 1) and $156 \mathrm{dpa}$ for $4000 \mathrm{keV}$ incident $\mathrm{Au}^{2+}$ ions (the 
Table 1

Chemical composition (wt.\%) of the ODS material after mechanical alloying.

\begin{tabular}{|c|c|c|c|c|c|c|c|c|c|}
\hline $\mathrm{Cr}$ & W & $\mathrm{Ti}$ & $\mathrm{Mn}$ & $\mathrm{Si}$ & $\mathrm{Ni}$ & $\mathrm{C}$ & $\mathrm{O}$ & $\mathrm{Y}_{2} \mathrm{O}_{3}$ & $\mathrm{Fe}$ \\
\hline 18.05 & 0.95 & 0.26 & 0.31 & 0.3 & 0.19 & 0.03 & 0.11 & 0.56 & Bal. \\
\hline
\end{tabular}

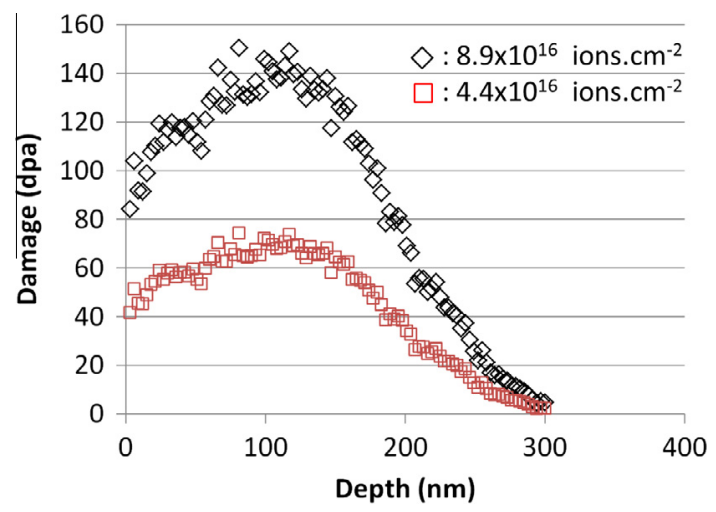

Fig. 1. Depth profile of displacement damage of $500 \mathrm{keV} \mathrm{Fe}$ ions in $\mathrm{Fe}$ calculated by SRIM (with $\mathrm{E}_{\mathrm{d}}(\mathrm{Fe})=40 \mathrm{eV}$ ).

damage depth profile will be presented later in this paper) . The irradiation parameters investigated in this study are summarized in Table 2.

\section{Results}

\subsection{Microstructure before irradiation}

The micrograph presented in Fig. 2a shows a bright-field TEM image of the typical microstructure of nanoparticles finely distributed in the ferritic matrix. As previously shown for this material [18], nanoprecipitates are dispersed throughout the grains with an average number density estimated to be $2.3 \times 10^{23} \mathrm{~m}^{-3}$. The particle diameters range from few nanometers to $10 \mathrm{~nm}$, with an average size of $1.5 \mathrm{~nm}$. Fig. $2 \mathrm{~b}$ presents a bright-field TEM image of one typical $2 \mathrm{~nm}$ particle.

One of these nanosized particles was further studied by HRTEM as shown in Fig. $3 \mathrm{a}$ and $\mathrm{b}$. The particle diameter is estimated to be $4.5 \mathrm{~nm}$. Evaluation of the HRTEM image by means of fast Fourier transform (FFT) (Fig. 3c) compared to simulated electron diffraction (Fig. 3d) indicates that interplanar distances and angles are consistent with the (004) and the $(2 \overline{2} 2)$ crystallographic planes of $\mathrm{Y}_{2} \mathrm{Ti}_{2} \mathrm{O}_{7}$ (pyrochlore, $a=1.009 \mathrm{~nm}$ ) in the [1 110$]$ zone axis for $d_{222}=0.29 \mathrm{~nm}, d_{004}=0.25 \mathrm{~nm}$ with $54.7^{\circ}$ between the $(2 \overline{2} 2)$ and $(004)$ planes. The orientation relationships between the oxide particles and the matrix were reported in a previous study by Ribis and de Carlan [25], and clearly show either a cube-on-cube or a cubeon-edge relationship. From the elasticity-driven morphology transition from sphere to cube, it has been concluded that particles must maintain strained coherent interfaces. As will be presented below in Section 3.3, similar results have been obtained in the present study. Thus, particles in the studied material are also expected to exhibit coherency strains.

Fig. $4 \mathrm{a}$ and $\mathrm{b}$ gives reconstructed APT results showing distributions of the $\mathrm{Fe}, \mathrm{Cr}, \mathrm{W}, \mathrm{Si}, \mathrm{Mn}$ in the matrix and $\mathrm{Y}, \mathrm{Cr}, \mathrm{Ti}$ and $\mathrm{O}$ in the clusters. The spatial distribution of oxygen is more diffuse than the other core elements, which is an artifact previously reported and discussed in the literature [17].

The chemical composition of matrix for the as-irradiated material as measured by APT is listed in Table $3 \mathrm{a}$.

The average composition of the nanoclusters was measured by APT using the method defined in Section 2, and is listed in Table $3 \mathrm{~b}$. The concentrations of core elements $\mathrm{Y}$ and $\mathrm{Ti}$ are 100 times higher compared to that measured from the matrix. Along with the core elements, a large portion of matrix elements were observed in the oxide clusters. This can be attributed to trajectory aberration associated with low-evaporation field particles embedded in a higher-field matrix. As reported by Williams et al. using APT, the local density of regions associated with nanoparticles increased by $\sim 4$, indicating the presence of extra atoms originating from the matrix [26]. In this work the exact quantity of $\mathrm{Fe}$ in the clusters was not addressed; instead the level of $\mathrm{Fe}$ in the clusters was set to zero and used to subtract the other matrix elements introduced by trajectory aberrations. The resulting compositions are quoted as "matrix-corrected" compositions and listed in Table 3c.

Although the HRTEM study indicates that oxide clusters have a structure consistent with a pyrochlore $\mathrm{Y}_{2} \mathrm{Ti}_{2} \mathrm{O}_{7}$ type, the APT-measured oxide composition deviates from the expected ratios, showing $\mathrm{Y} / \mathrm{Ti}=0.6$ and $(\mathrm{Y}+\mathrm{Ti}) / \mathrm{O}=5.5$. Furthermore, the APT measurements show that these nanoparticles are still rich in $\mathrm{Cr}$ after applying a correction for the local focusing effect. The nanoparticles are thus more likely to be $\mathrm{Y}-\mathrm{Ti}-\mathrm{Cr}$-rich oxides.

\subsection{Microstructure after irradiation}

Compared to the non-irradiated state in Fig. 5a and b, the microstructure of oxide clusters after irradiation to $150 \mathrm{dpa}$ at $500{ }^{\circ} \mathrm{C}$ is presented in Fig. $5 \mathrm{c}$ and d. The nanoparticles have evolved during irradiation: their sizes are larger and their shapes are more clearly defined and appear as cuboidal. The histograms presented on Fig. 6 highlight this evolution of the nanoparticle size distribution from 0 to 74.4 to $150 \mathrm{dpa}$. Because there is a shape evolution, the equivalent diameter $d_{e q}$ of the cubical particle is estimated using the relation $a^{2}=\pi d_{e q}^{2}$, where $a$ is the particle edge. Before irradiation, the particle size ranges from 0.5 to 
Table 2

Irradiation damage characteristics.

\begin{tabular}{llrrllcl}
\hline $\begin{array}{l}\text { Incidence angle } \\
\left({ }^{\circ}\right)\end{array}$ & Ions & $\mathrm{E}(\mathrm{keV})$ & $\mathrm{T}\left({ }^{\circ} \mathrm{C}\right)$ & $\begin{array}{l}\text { Flux } \\
\left(\text { ions cm }{ }^{-2} \mathrm{~s}^{-1}\right)\end{array}$ & $\begin{array}{l}\text { Total fluence } \\
\left(\text { ions cm } \mathrm{cm}^{-2}\right.\end{array}$ & Dose max. (dpa) & $\begin{array}{l}\text { Average ion implantation } \\
(\text { at. } \%)\end{array}$ \\
\hline 15 & $\mathrm{Fe}^{+}$ & 500 & 500 & $2.8 \times 10^{12}$ & $4.4 \times 10^{16}$ & 74.4 & 1.3 \\
15 & $\mathrm{Fe}^{+}$ & 500 & 500 & $2.6 \times 10^{12}$ & $8.9 \times 10^{16}$ & 150 & 2.7 \\
72 & $\mathrm{Au}^{2+}$ & 4000 & 25 & $7.9 \times 10^{10}$ & $9.5 \times 10^{15}$ & 156 & 0.4 \\
\hline
\end{tabular}

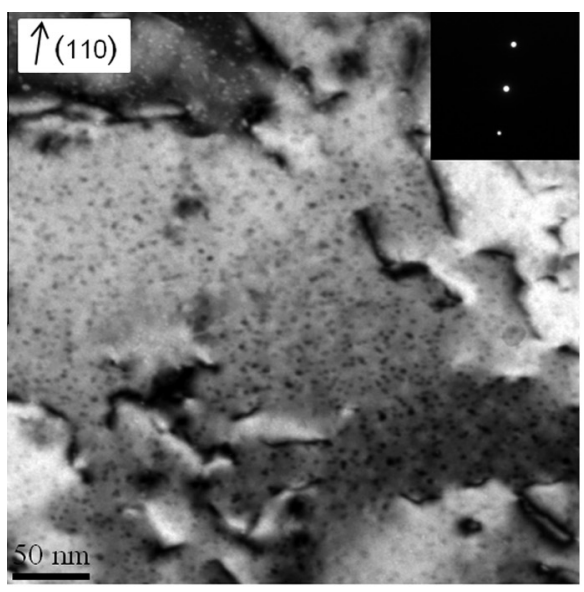

(a)

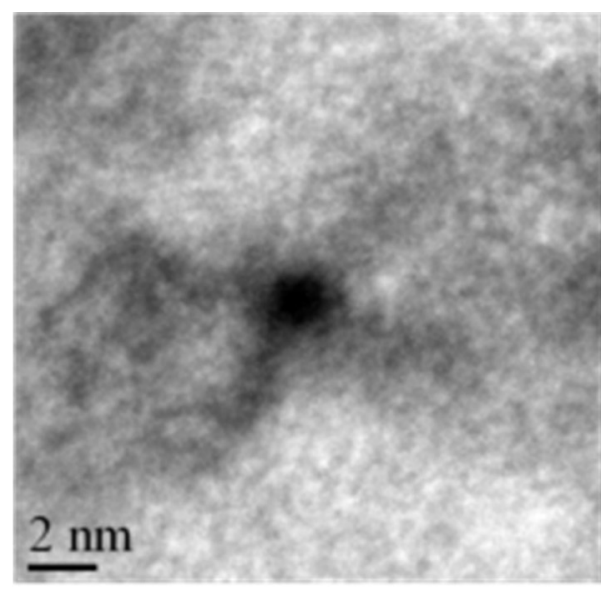

(b)

Fig. 2. Oxide dispersion before irradiation: (a) nano-oxide distribution; (b) a $2 \mathrm{~nm}$ nano-oxide particle.

$10 \mathrm{~nm}$ centered on $3 \mathrm{~nm}$. At $74.4 \mathrm{dpa}$, the particle size is centered on $3.5 \mathrm{~nm}$, and at $150 \mathrm{dpa}$, the histogram presents a wider distribution of nanoparticles, centered on 4 $4.5 \mathrm{~nm}$. As suggested by comparing Figs. 2 and 5, nanoparticles tend to grow under irradiation at $500{ }^{\circ} \mathrm{C}$. Further, a decrease in the number density with increasing irradiation dose is measured. Table 4 summarizes these results.

The APT reconstruction of the $150 \mathrm{dpa}$ sample is presented in Fig. 7. It is similar to the non-irradiated sample in which $\mathrm{Fe}, \mathrm{Cr}, \mathrm{W}, \mathrm{Si}$ and $\mathrm{Mn}$ show uniform distribution in the matrix after irradiation. The matrix concentration is unchanged compared to that observed before irradiation (Table 5a).

Table $5 \mathrm{~b}$ and $\mathrm{c}$ gives the uncorrected and corrected atomic composition for the clusters, respectively. It is important to notice that after irradiation up to $150 \mathrm{dpa}$, the relative composition has evolved: $\mathrm{Y} / \mathrm{Ti}=0.78$ and $(\mathrm{Y}+\mathrm{Ti}) / \mathrm{O}=3.57$, which is closer to the expected equilibrium phase composition of $\mathrm{Y}_{2} \mathrm{Ti}_{2} \mathrm{O}_{7}$. Further, the Cr content has been reduced from 48 to 26 at. $\%$ after irradiation at 150 dpa. Fig. 8 compares the $\mathrm{Y} / \mathrm{Ti}$ ratio prior and after irradiation as a function of the nanoparticle size. Prior to irradiation (Fig. 8a), this ratio is size independent, while after irradiation (Fig. 8b) the larger the particles, the higher the ratio, suggesting that the larger particles have gathered preferentially $\mathrm{Y}$ with respect to Ti.

Fig. 9a shows a typical example of the high-resolution images obtained from the $150 \mathrm{dpa}$ irradiated material, along with the associated FFT (Fig. 9b). In most cases, it was not possible to obtain any clear HRTEM information from the nanoparticles themselves. The ferritic matrix contributes almost exclusively to the HR signal. No clear conclusion can thus be made as to whether the particles are crystalline or amorphous in structure. However, as shown in Fig. 9d, the edges of the cuboidal particle are parallel to the $\langle 100\rangle$ matrix direction; we can also observe that the particle presents a ledge parallel to the $\langle 011\rangle$ direction.

\subsection{Microstructure after high-temperature anneal}

Fig. 10a presents the microstructure before the heat treatment obtained by TEM, while Fig. $10 \mathrm{~b}$ presents it after heat treatment at $1300{ }^{\circ} \mathrm{C}$ for $1 \mathrm{~h}$. The shape bifurcation from spherical to cubic particles can be clearly seen. In addition, Fig. 10c shows the corresponding histogram of precipitate size. The mean diameter of the particles has evolved from 1.5 to $4.5 \mathrm{~nm}$ with annealing. To facilitate the comparison with the irradiated material, the mean diameter of the particles after irradiation at $500{ }^{\circ} \mathrm{C}$ to $150 \mathrm{dpa}$ is marked on Fig. 10c with a red dotted line.

\section{Discussion}

\subsection{Before irradiation}

The APT results suggest that nanoparticles have Y-Ti and $\mathrm{O} /(\mathrm{Y}+\mathrm{Ti})$ ratios that are too low to be consistent with the $\mathrm{Y}_{2} \mathrm{Ti}_{2} \mathrm{O}_{7}$ structure found by TEM for particles 


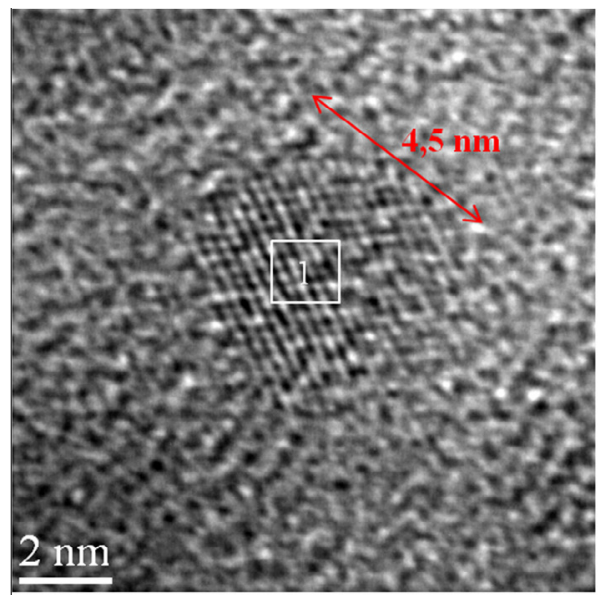

(a)

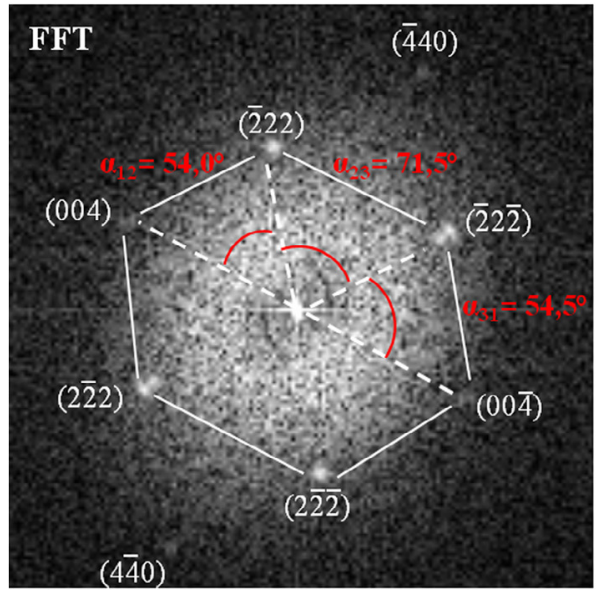

(c)

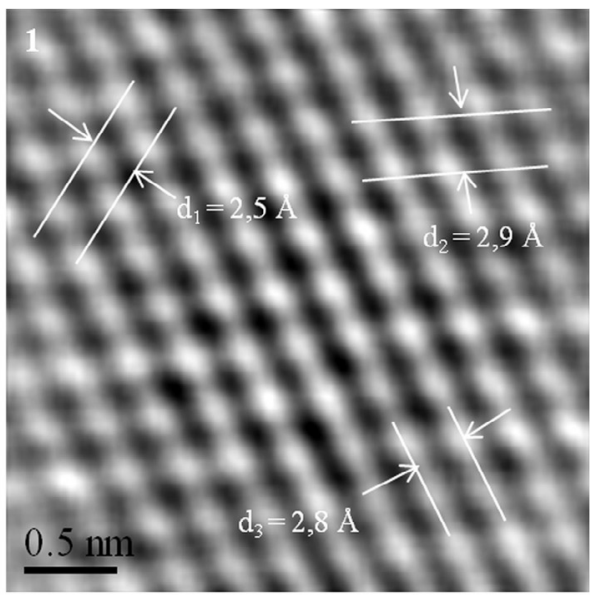

(b)

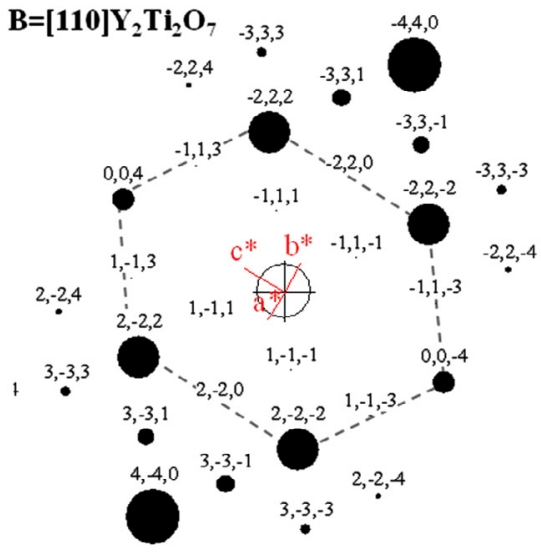

(d)

Fig. 3. TEM characterization of a nanoparticle in the non-irradiated sample: (a) high-resolution image of a nanoparticle; (b) zoom on (a); (c) FFT of (a); (d) simulated diffractogram of a pyrochlore-type structure compared to the FFT presented in (c).

$>4.5 \mathrm{~nm}$. Similar non-stoichiometric compositions have been reported in several ODS steels [27-30] and also by TEM investigations [31].

While the measured compositions may be affected by evaporation artefacts $[32,33,17]$, independent TEM measurement have also confirmed that nanoparticles can have far from the expected equilibrium compositions. For instance, using energy-filtered TEM, Lozano-Perez et al. [34] observed that the majority of analyzed particles seemed to have a $\mathrm{Cr}+\mathrm{Y}+\mathrm{O}$-rich core with variable $\mathrm{Cr}$ content. Further, using energy-dispersive $\mathrm{X}$-ray spectrometry, Sakasegawa et al. [35] concluded that particles from 2 to $15 \mathrm{~nm}$ are non-stoichiometric, while particles from 15 to $35 \mathrm{~nm}$ have the expected $\mathrm{Y}_{2} \mathrm{Ti}_{2} \mathrm{O}_{7}$ stoichiometry. Williams et al. [17] provided similar results obtained by APT and found that the stoichiometry change can occur at smaller sizes with a shift of the $\mathrm{Y} / \mathrm{O}$ ratio from $\sim 1: 2$ in the $2 \mathrm{~nm}$ particles to 1:1 for 5-10 nm particles. Further, Sakasegawa et al. [36] reported that, after thermal annealing at $1200{ }^{\circ} \mathrm{C}$ for $1 \mathrm{~h}$, some $\mathrm{Y}_{\mathrm{x}} \mathrm{Ti}_{\mathrm{y}} \mathrm{O}_{\mathrm{z}}$ particles transformed to $\mathrm{Y}_{2} \mathrm{Ti}_{2} \mathrm{O}_{7}$ particles. Dawson and Tatlock [37] analyzed the structure of $5 \mathrm{~nm}$ diameter particles after thermal annealing $\left(1300{ }^{\circ} \mathrm{C}\right.$ for $\left.1 \mathrm{~h}\right)$ by means of high-angular annular dark-field microscopy and found that the intensity profiles measured along adjacent $\{004\}$ atomic planes were consistent with the cationic sublattice of the pyrochlore crystal structure. They concluded that the particle concerned possesses the ordered pyrochlore structure.

From the above discussion, it is reasonable to suppose that small nanoparticles are non-stoichiometric $\mathrm{Y}-\mathrm{Ti}-\mathrm{Cr}-$ $\mathrm{O}$ with a pyrochlore-type structure, as proposed by Yamashita et al. [31], who believe that the $\mathrm{Y}_{2} \mathrm{Ti}_{2} \mathrm{O}_{7}$ structure can tolerate a high concentration of point defects. However, the atomic arrangement of $\mathrm{Cr}$ in the pyrochlore-type structure remains unclear. Further, it can be imagined that, when growing during thermal annealing, non-stoichiometric nanoclusters, with a pyrochlore-type structure, may relax toward the stoichiometric $\mathrm{Y}_{2} \mathrm{Ti}_{2} \mathrm{O}_{7}$ equilibrium composition as also observed under irradiation and discussed below.

\subsection{Irradiation at $500^{\circ} \mathrm{C}$}

The present study found that after self $\mathrm{Fe}^{+}$implantation to $150 \mathrm{dpa}$ at $500{ }^{\circ} \mathrm{C}$, a high number density of nanoparticles is still present. The atom displacements caused by 
$\mathrm{Fe}$

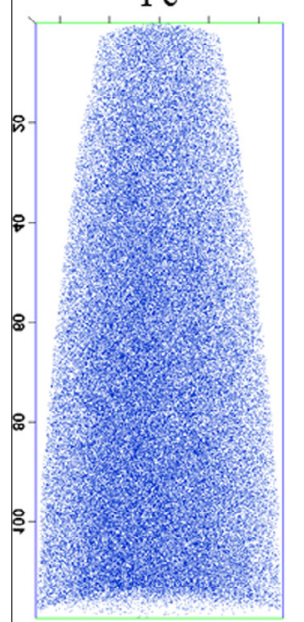

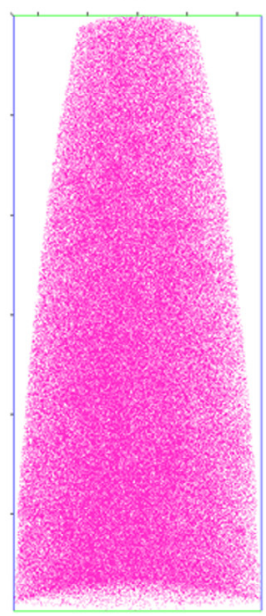

W

$\mathrm{Si}$

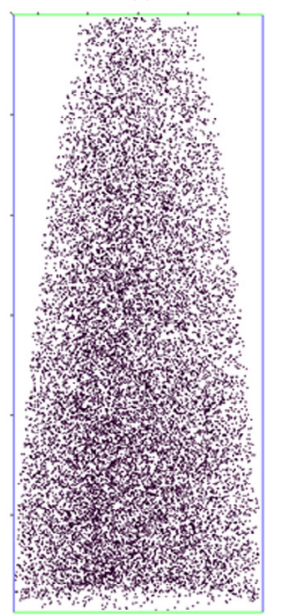

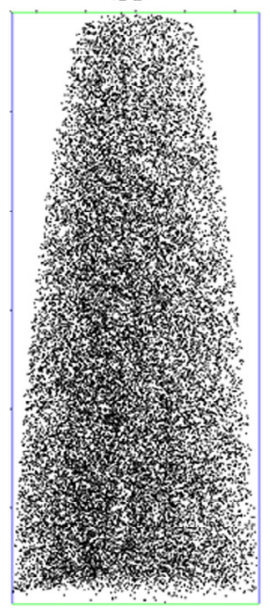

$\mathrm{Mn}$

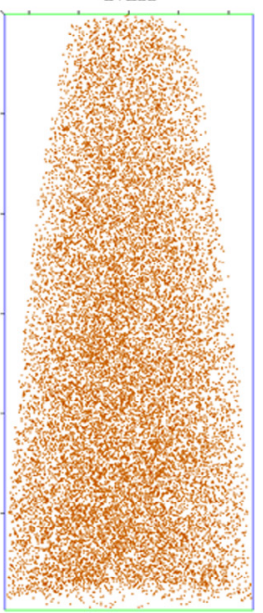

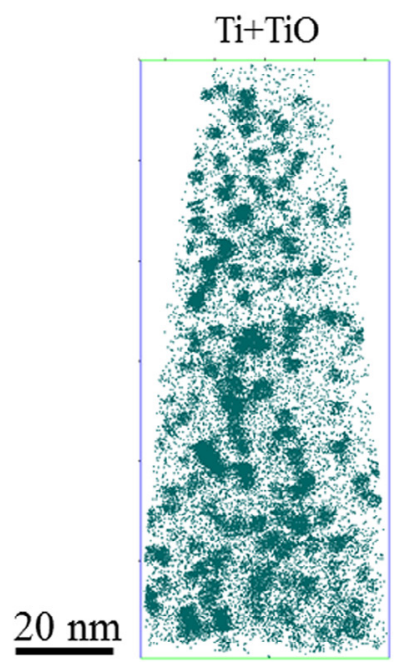
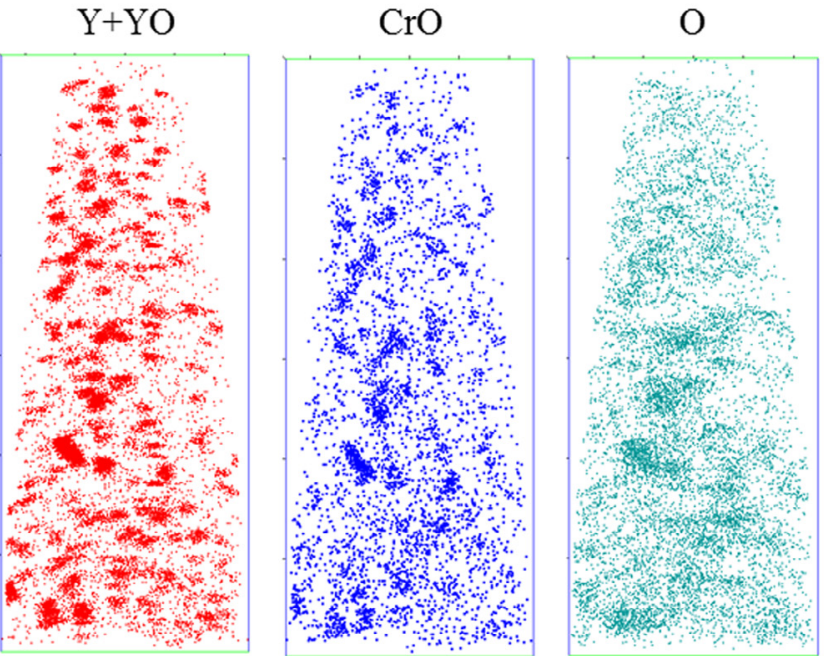

Fig. 4. 3-D APT reconstruction from the $\mathrm{Fe} 18 \mathrm{Cr}-\mathrm{Y}_{2} \mathrm{O}_{3}$ material before irradiation showing the distribution of evaporated elements or molecules.

Table 3

APT measurement of (a) matrix composition before irradiation, (b) nanoparticle (uncorrected composition), (c) nanoparticle (corrected composition).

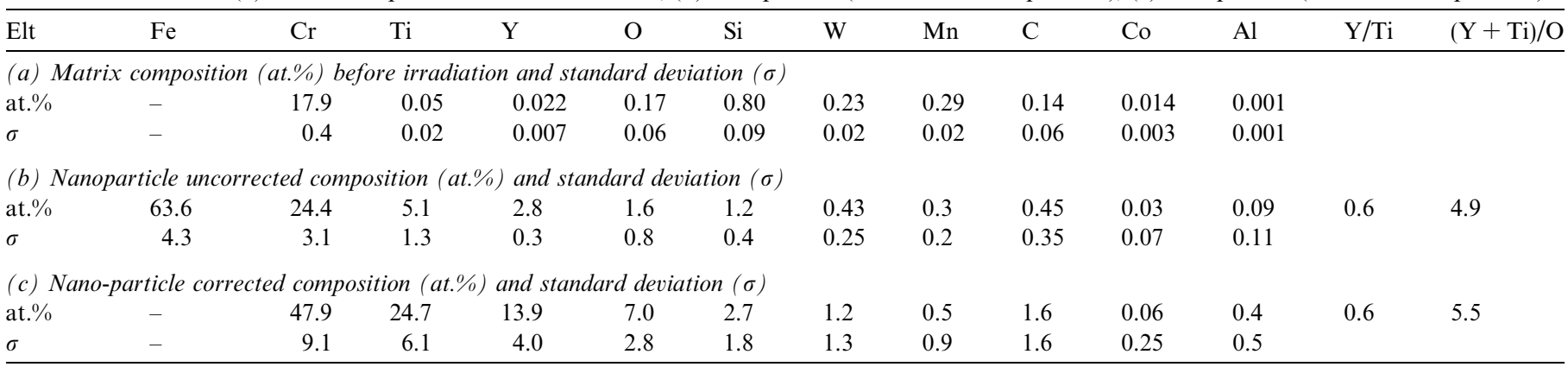

cascades can modify the kinetic equilibrium of the nanoparticles and therefore lead to an evolution of the nanoparticles. Since particle growth was observed instead of particle dissolution, it would appear that for the set of experiments conducted at $500{ }^{\circ} \mathrm{C}$, the system is operating under accelerated diffusion.

If $\tau$ is the characteristic time required for vacancies to reach the sinks, it can be expressed as: $\tau=\frac{1}{k^{2} D_{V}}$,

with $k$ the sink strength and $D_{V}$ the vacancy coefficient diffusion. Assuming that the nanoparticles behave as perfect sinks for point defects, the sink strength is expressed as [38]:

$k^{2}=4 \pi R_{p} N_{p}$, 


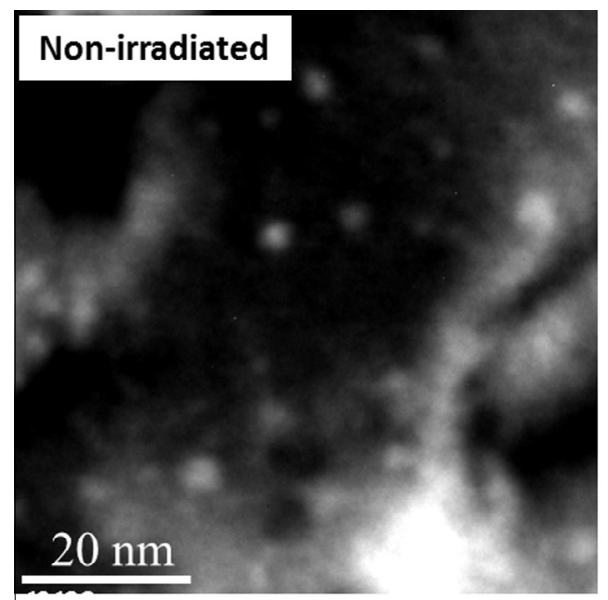

(a)

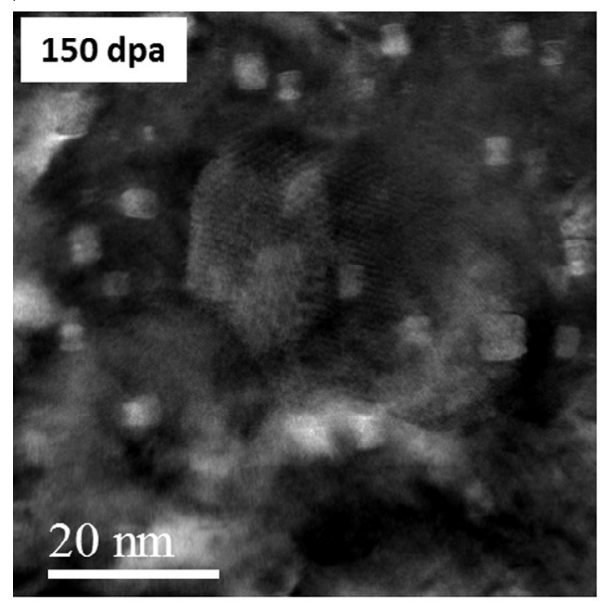

(c)

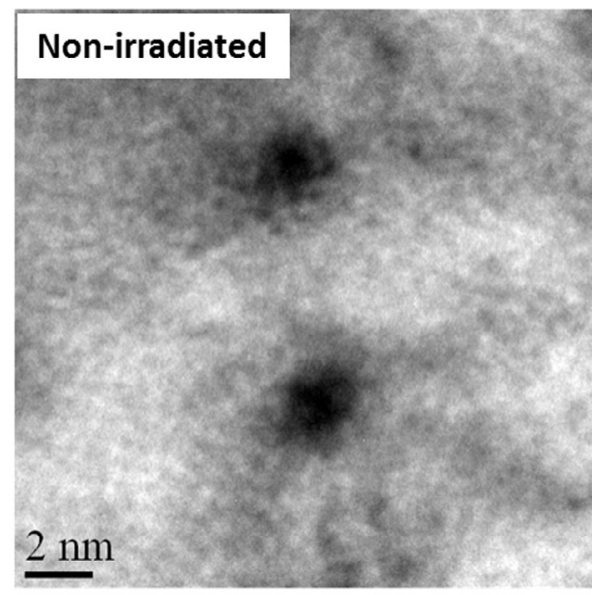

(b)

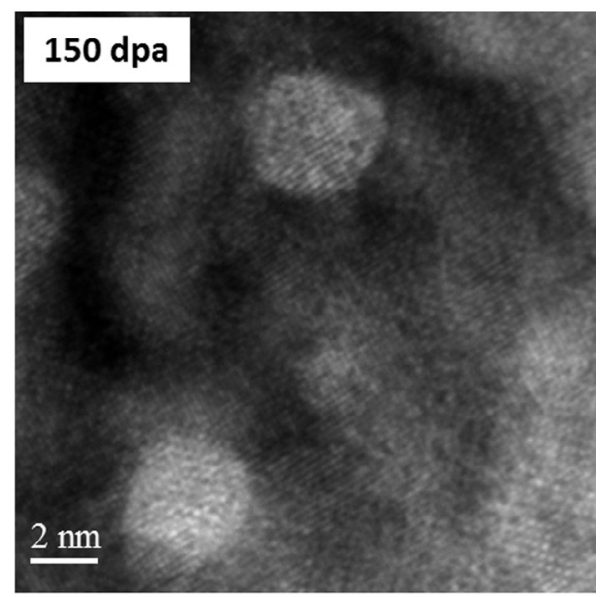

(d)

Fig. 5. Evolution of the nanoparticles after irradiation: (a) nanoparticle distribution prior to irradiation; (b) two nanoparticles prior to irradiation; (c) nanoparticle distribution after $150 \mathrm{dpa}$ at $500{ }^{\circ} \mathrm{C}$; (d) two nanoparticles after $150 \mathrm{dpa}$ at $500{ }^{\circ} \mathrm{C}$.

where $R_{p}=1.5 \mathrm{~nm}$ and $N_{p}=2.3 \times 10^{23} \mathrm{~m}^{-3}$ are the nanoparticle mean diameter and density measured experimentally by TEM. Thus, the estimated sink strength $k^{2}$ is $4.3 \times 10^{11} \mathrm{~cm}^{-2}$.

The vacancy diffusion coefficient is determined using [38]:

$D_{V}=\alpha a^{2} v \exp \left(-\frac{E_{V}^{m}}{k_{B} T}\right)$,

where $T$ is the temperature and $k_{B}$ is the Boltzmann constant, $\alpha$ is a geometric factor equal to $1, a=0.287 \mathrm{~nm}$ is the lattice parameter for body-centered cubic (bcc) Fe, $v$ can be taken as the Debye frequency $\left(v=10^{13} \mathrm{~s}^{-1}\right)$, and $E_{V}^{m}=0.7 \mathrm{eV}$ is the vacancy migration energy [39]. Thus the vacancy diffusion coefficient at $500^{\circ} \mathrm{C}$ is $D_{V}=$ $2.24 \times 10^{-7} \mathrm{~cm}^{2} \mathrm{~s}^{-1}$. Therefore, the time $\tau$ for vacancies to arrive at sinks is $\sim 10^{-5} \mathrm{~s}$, which is significantly shorter than the irradiation time $\left(3.4 \times 10^{4} \mathrm{~s}\right)$. In this regime, the steady-state non-equilibrium vacancy concentration is governed by the sink densities and is given by:

$C_{V}^{I r r}=R \tau$, where $R$ is the defect production rate equal to $6.4 \times 10^{-3}$ $\mathrm{dpa} \mathrm{s}^{-1}$. The non-equilibrium vacancy concentration is therefore equal to $6.5 \times 10^{-8}$.

Assuming at $500{ }^{\circ} \mathrm{C}$ a vacancy mechanism for the diffusion of a given species, its radiation-enhanced diffusion coefficient is then defined as:

$D^{I r r}=\frac{C_{V}^{I r r}}{C_{V}^{\text {eq }}} D^{t h}=R \tau \exp \left(\frac{E_{V}^{f}}{k_{B} T}\right) D^{t h}$,

where $C_{V}^{e q}$ is the thermal equilibrium vacancy concentration, $E_{V}^{f}$ is the vacancy formation energy and $D^{\text {th }}$ is the thermal diffusion coefficient. The values for pure bcc Fe, $E_{V}^{f}=2.2 \mathrm{eV}$ [39], yield $D^{I r r}=1.4 \times 10^{7} D^{t h}$.

Because of its slow diffusion compared to the other elements, oxide growth is assumed to be controlled by the diffusion of $\mathrm{Y}$ in Fe. Using $D^{t h}=D_{Y}^{t h}=0.1 \exp \left(\frac{-3.25}{k_{B} T}\right)$ [40], the diffusion coefficient of $Y$ under the considered irradiation conditions at $500{ }^{\circ} \mathrm{C}$ is $D_{Y}^{I r r} \approx 9 \times 10^{-16} \mathrm{~cm}^{2} \mathrm{~s}^{-1}$.

This value needs to be compared with the ballistic diffusion coefficient: 


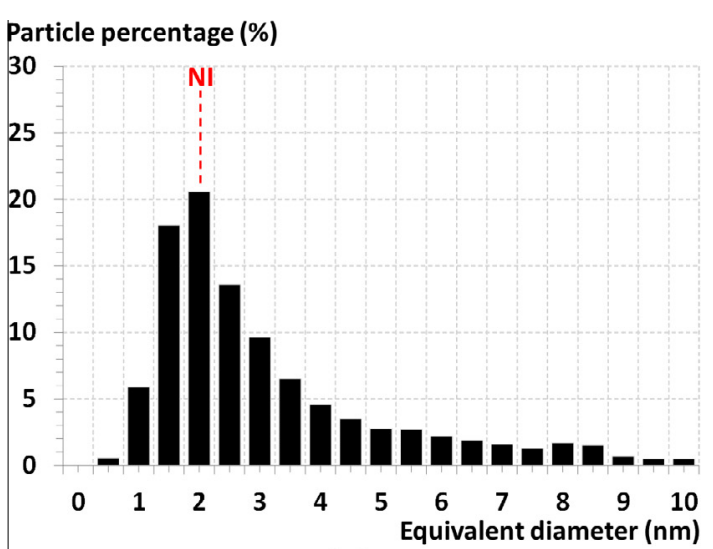

(a)

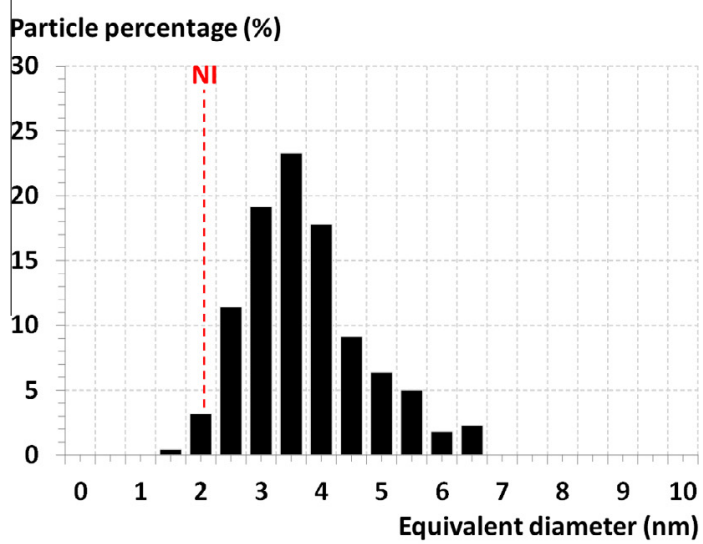

(b)

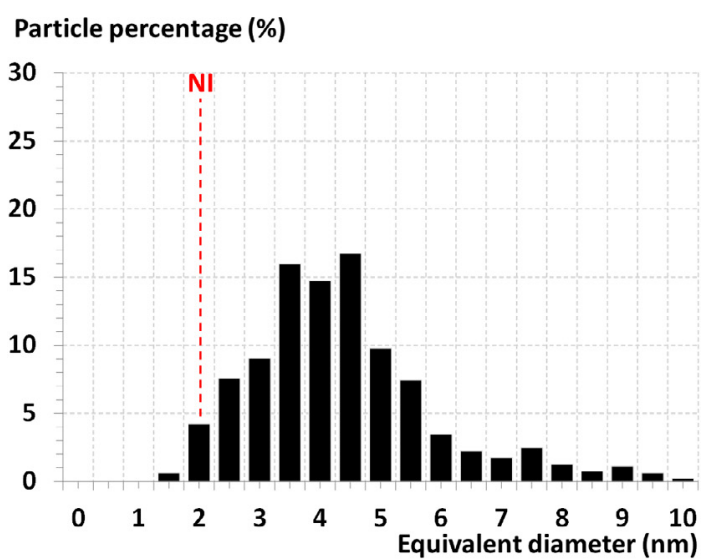

(c)

Fig. 6. Evolution of the nanoparticle distribution during irradiation: (a) nanoparticle distribution prior to irradiation; (b) nanoparticle distribution after irradiation at $500^{\circ} \mathrm{C}$ up to $74.4 \mathrm{dpa}$; (c) nanoparticle distribution after irradiation at $500^{\circ} \mathrm{C}$ up to $150 \mathrm{dpa}$.

Table 4

Parameters of nanoparticle distribution after irradiation at $500{ }^{\circ} \mathrm{C}$ up to 0 , 74.4 and 150 dpa.

\begin{tabular}{cll}
\hline Dose $(\mathrm{dpa})$ & Equivalent diameter $(\mathrm{nm})$ & Density $\left(\mathrm{m}^{-3}\right)$ \\
\hline 0 & $3.0 \pm 0.5$ & $(2.3 \pm 0.7) \times 10^{23}$ \\
74.4 & $3.5 \pm 0.5$ & $(1.1 \pm 0.3) \times 10^{23}$ \\
150 & $4.1 \pm 0.5$ & $(0.9 \pm 0.3) \times 10^{23}$ \\
\hline
\end{tabular}

$D^{B}=\frac{1}{6} R\left\langle\bar{x}^{2}\right\rangle$

where $\bar{x}$ is the average distance that $\mathrm{Y}$ atoms travel due to the cascade collisions.

To estimate $\bar{x}$, Heining et al. [41] proposed calculating the spatial probability distribution $f(\delta)$ of atoms displaced out of the particle, where $\delta$ is the distance of the displaced atom from its original position. By considering a flat interface, Heining et al. [41] showed that this distribution could be expressed as $f(\delta)=q / 2(1+\delta / 2 \lambda) \exp [-\delta / \lambda]$, where $q$ is a constant and $\lambda$ is the mean displacement distance. The parameters $q$ and $\lambda$ are determined by means of TRIM calculation for a thin slab of $\mathrm{Y}_{2} \mathrm{Ti}_{2} \mathrm{O}_{7}$ immersed in an $\mathrm{Fe}$ matrix submitted to our experimental irradiation parameters. The spatial probability distribution of displaced atoms is fitted on the TRIM results for forward and backward transported $\mathrm{Y}$ recoils.

Taking into account both forward and backward profiles, $\bar{x}$ is in the range $0.25-0.35 \mathrm{~nm}$, which gives an estimate of $D^{B}$ of between $6.7 \times 10^{-19}$ and $1.3 \times 10^{-18} \mathrm{~cm}^{2} \mathrm{~s}^{-1}$, well below the estimated value of $D^{i r r}$. According to the previous analysis, at $500{ }^{\circ} \mathrm{C}$ the main effect of irradiation is to enhance the thermal diffusion due to the high concentration of vacancies reached at the steady sate.

Thus, the system is driven toward the thermodynamic equilibrium under the irradiation conditions considered at $500^{\circ} \mathrm{C}$.

\subsection{Comparison with high-temperature annealing}

The evolution of the microstructure after heat treatment at high temperature $\left(1300^{\circ} \mathrm{C}\right)$ can be considered as a reference with which the evolution under irradiation can be compared.

TEM observations revealed an increase of particle size and a decrease of their density with increasing irradiation dose at $500{ }^{\circ} \mathrm{C}$. At $150 \mathrm{dpa}$, the size of the nanoparticles evolved from 3.0 to $4.1 \mathrm{~nm}$, with a density three times lower than before irradiation (Table 4). An evolution from spherical to cubic shape is also observed, in agreement with previous observations [25].

The cube of the precipitate size and the inverse of the precipitate density $(1 / \rho)$ are plotted in Fig. 11 as a function of irradiation time. Linear dependences of the diameter with $\mathrm{t}^{1 / 3}$ and the density with $\mathrm{t}^{-1}$ are obtained. These results are consistent with the LSW theory [42], which supports the hypothesis of an Ostwald ripening mechanism under irradiation.

A comparison of the microstructure after irradiation at $500{ }^{\circ} \mathrm{C}$ up to $150 \mathrm{dpa}$ and after a thermal treatment of $1 \mathrm{~h}$ at $1300{ }^{\circ} \mathrm{C}$ suggests that both processes induce a similar oxide nanocluster evolution. Moreover, in both cases, the increase of the mean nanocluster size induces a morphology evolution from spherical to cubic shapes. This comparison supports the hypothesis that the most important effect of irradiation at $500{ }^{\circ} \mathrm{C}$ is to increase the kinetics effects, 

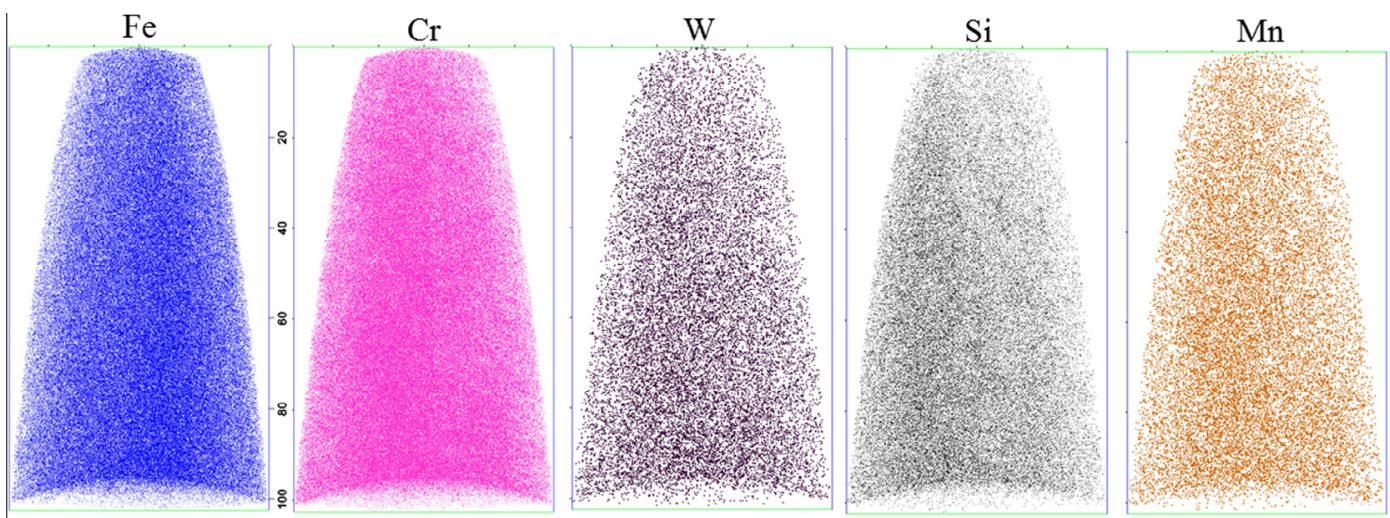

$\underline{20 \mathrm{~nm}}$
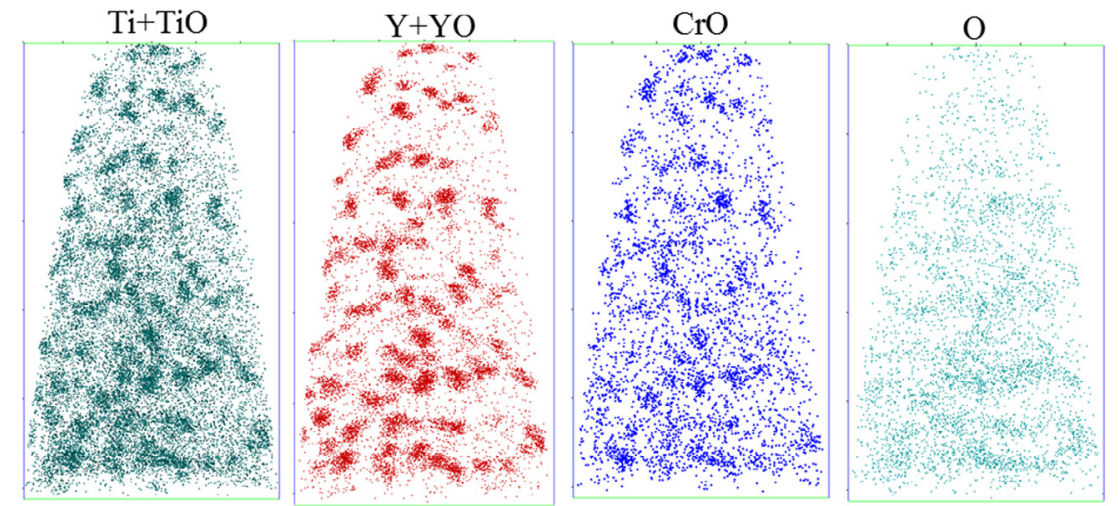

Fig. 7. 3-D APT reconstruction from the $\mathrm{Fe} 18 \mathrm{Cr}-\mathrm{Y}_{2} \mathrm{O}_{3}$ material after irradiation at $500{ }^{\circ} \mathrm{C}$ up to 150 dpa showing the distribution of evaporated elements and molecules.

Table 5

APT measurement of matrix composition after irradiation $\left(500^{\circ} \mathrm{C}, 150 \mathrm{dpa}\right)$.

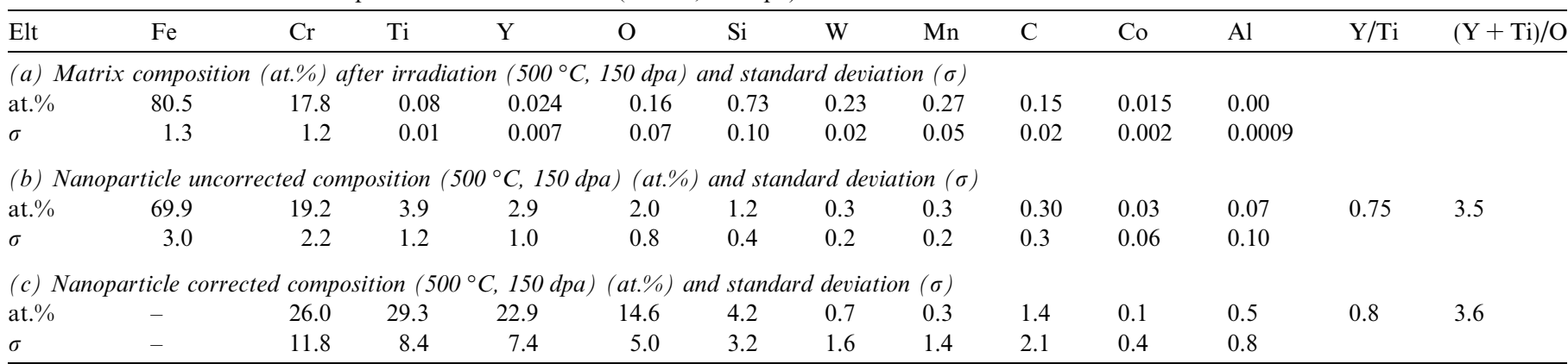

and therefore favor a faster evolution towards thermodynamic equilibrium. This analysis is supported by the APT measurements that indicate a preferential loss of $\mathrm{Cr}$ and also a change in the ratio of $\mathrm{Y} / \mathrm{Ti}$ and $(\mathrm{Y}+\mathrm{Ti}) / \mathrm{O}$ prior to and after irradiation. Before irradiation, the nanoparticles have been found to be non-stoichiometric $\mathrm{Y}-\mathrm{Ti}-\mathrm{Cr}-\mathrm{O}$ with the pyrochlore-type structure, based on HRTEM observation on one of these particles. After $150 \mathrm{dpa}$, however, the oxide composition determined by APT tends to indicate that the particles might have evolved towards a more stoichiometric composition, closer to that of $\mathrm{Y}_{2} \mathrm{Ti}_{2} \mathrm{O}_{7}$. This could be correlated with the loss of $\mathrm{Cr}$, which is more soluble in the $\mathrm{Fe}$ matrix than in the $\mathrm{Y}-\mathrm{Ti}-\mathrm{O}$ system [43]. Thus, the equilibrium configuration under irradiation at temperature $\mathrm{T}$ and flux $\phi$ would correspond to the equilibrium configuration without irradiation at a higher temperature [44].

From a quantitative point of view, $D_{Y}^{\text {th }}$ $\left(1300^{\circ} \mathrm{C}\right)=3.8 \times 10^{-12} \mathrm{~cm}^{2} \mathrm{~s}^{-1}$. The comparable nanoparticle evolutions observed after the thermal treatment and the irradiation experiment would suggest that the diffusion kinetics are also comparable, i.e. $D^{I r r}\left(500^{\circ} \mathrm{C}\right)=D_{Y}^{t h}$ $\left(1300^{\circ} \mathrm{C}\right) / 10=3.8 \times 10^{-13} \mathrm{~cm}^{2} \mathrm{~s}^{-1}$. This value is, however, more than two orders of magnitude above the value previously calculated using the steady-state concentration of vacancies. This disagreement may be due to an overestimation of $D_{Y}^{\text {th }}\left(1300^{\circ} \mathrm{C}\right)$, an underestimation of $C_{V}^{I r r}$, or a combination of both effects. It may also be due to other 


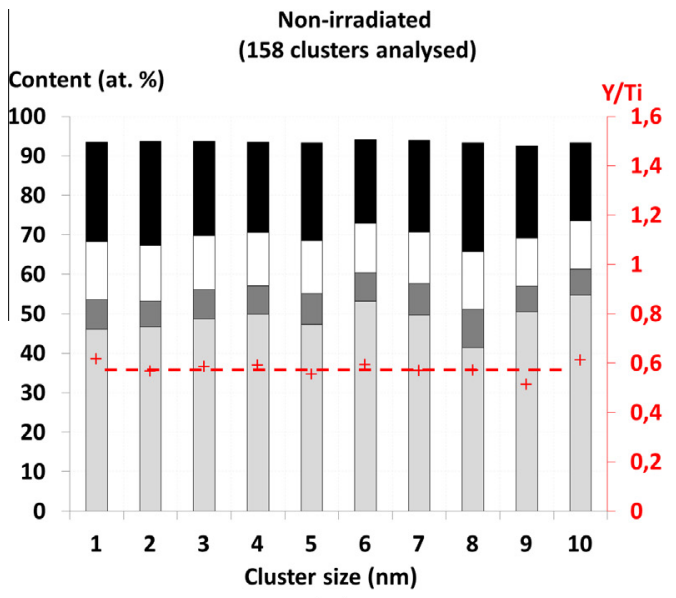

(a)

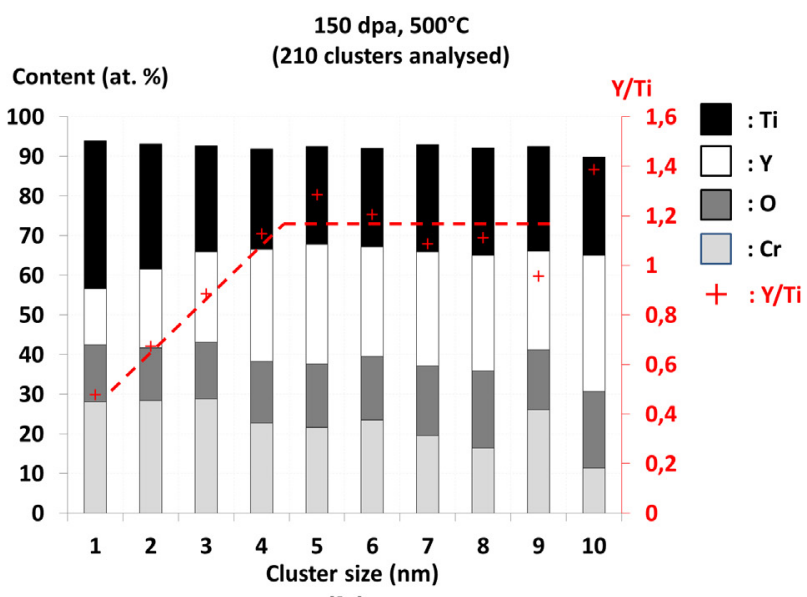

(b)

Fig. 8. Comparison of the element content in nanoparticles (a) prior to and (b) after $150 \mathrm{dpa}$ at $500{ }^{\circ} \mathrm{C}$.

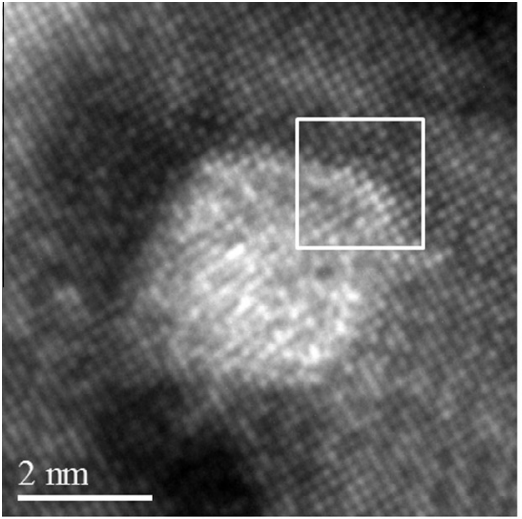

(a)

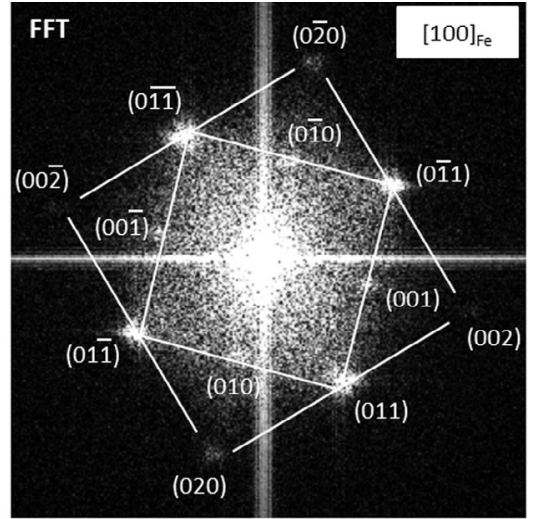

(b)

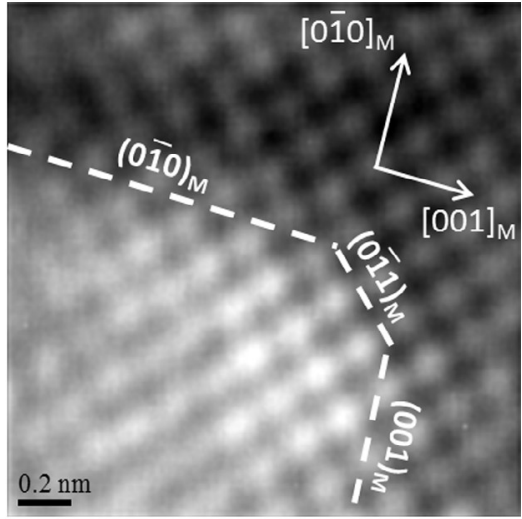

(c)

Fig. 9. High-resolution image of a nanoparticle after 150 dpa at $500{ }^{\circ} \mathrm{C}$ : (a) the nanoparticle; (b) FFT of (a); (c) HRTEM of the matrix; (d) HRTEM of the nanoparticle-matrix interface.

processes such as interstitial diffusion, which was not considered in the present discussion but may contribute to an accelerated diffusion under irradiation.

\subsection{Room-temperature irradiation}

At sufficiently low temperatures, irradiation will only produce ballistic diffusion which favors the homogenization of chemical species (production of an homogeneous solid solution) contrary to enhanced diffusion which favors the homogenization of the chemical potential (accelerated motion towards equilibrium). To validate this hypothesis, irradiation experiments were conducted at room temperature using $\mathrm{Au}^{2+}$ ions. A fluence of $9.5 \times 10^{15}$ ions $\mathrm{cm}^{-2}$ resulted in $156 \mathrm{dpa}$ in the thin-foil depth at a flux $\mathrm{R}=1.29 \times 10^{-3} \mathrm{dpa} \mathrm{s}^{-1}$. The APT measurements, presented in Fig. 12, clearly show that in the irradiated zone, where the damage reaches $156 \mathrm{dpa}$, the nanoparticles are completely dissolved. However, when the irradiation damage is lower, at larger depths, nanoparticles remain in the ferritic matrix. This result illustrates the effect of the ballistic jumps, which seem to be larger than enhanced diffusion at this temperature.

From Eq. (3), the vacancy diffusion coefficient at $25^{\circ} \mathrm{C}$ is $D_{v}=1.4 \times 10^{-20} \mathrm{~cm}^{2} \mathrm{~s}^{-1}$ and using Eq. (1), $\tau=1888$ years, which means that during irradiation the regime of annihilation at sinks is far from being reached. The characteristic time $\tau_{\rho}$ to reach the recombination regime is given by $\tau_{\rho}=\left(1 /\left(\mathrm{RK}_{\mathrm{IV}}\right)^{1 / 2}\right.$, where $\mathrm{K}_{\mathrm{IV}}$ is the recombination rate of vacancies and interstitials and $R$ is the flux. If $v_{\mathrm{i}}=v \exp \left(-\mathrm{E}_{\mathrm{I}}^{\mathrm{m}} / \mathrm{k}_{\mathrm{B}} \mathrm{T}\right)$ is the jump frequency of interstitials, $\mathrm{K}_{\mathrm{IV}} \approx 200 v_{\mathrm{I}}$ [38]. Taking typical values $\left(v=10^{13} \mathrm{~Hz}, \mathrm{E}_{\mathrm{I}}^{\mathrm{m}}=0.65 \mathrm{eV}\right.$ [39]) gives $\tau_{\rho}=0.2 \mathrm{~s}$, which clearly indicates that the irradiation at room temperature was performed in the recombination regime. In this regime, the concentration of vacancies is equal to that of interstitials and is given by $C_{V}^{\text {Irr }}=\left(R / K_{I V}\right)^{1 / 2}$, which gives in our case $\mathrm{C}_{\mathrm{V}}^{\mathrm{Irr}}=2.4 \times 10^{-4}$, leading to irradiation-enhanced diffusion coefficient $D^{\mathrm{Irr}}=210^{-22} \mathrm{~cm}^{2} \mathrm{~s}^{-1}$ from Eq. (5). This value has to be compared with the ballistic diffusion 


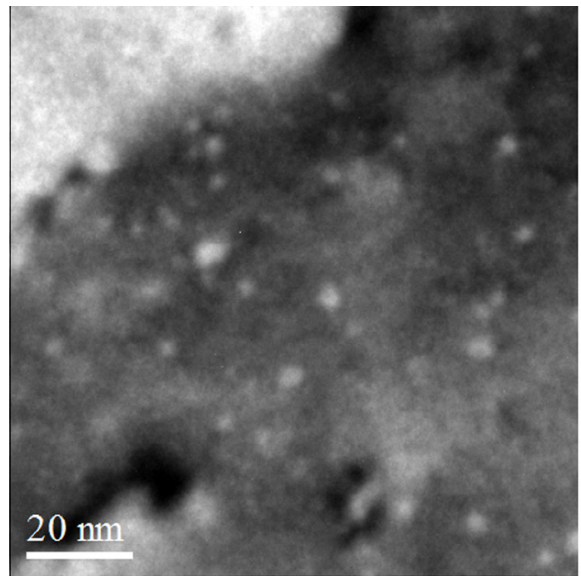

(a)

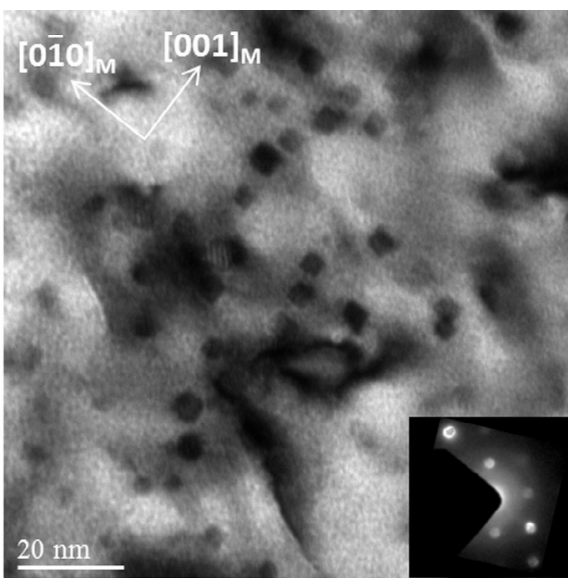

(b)

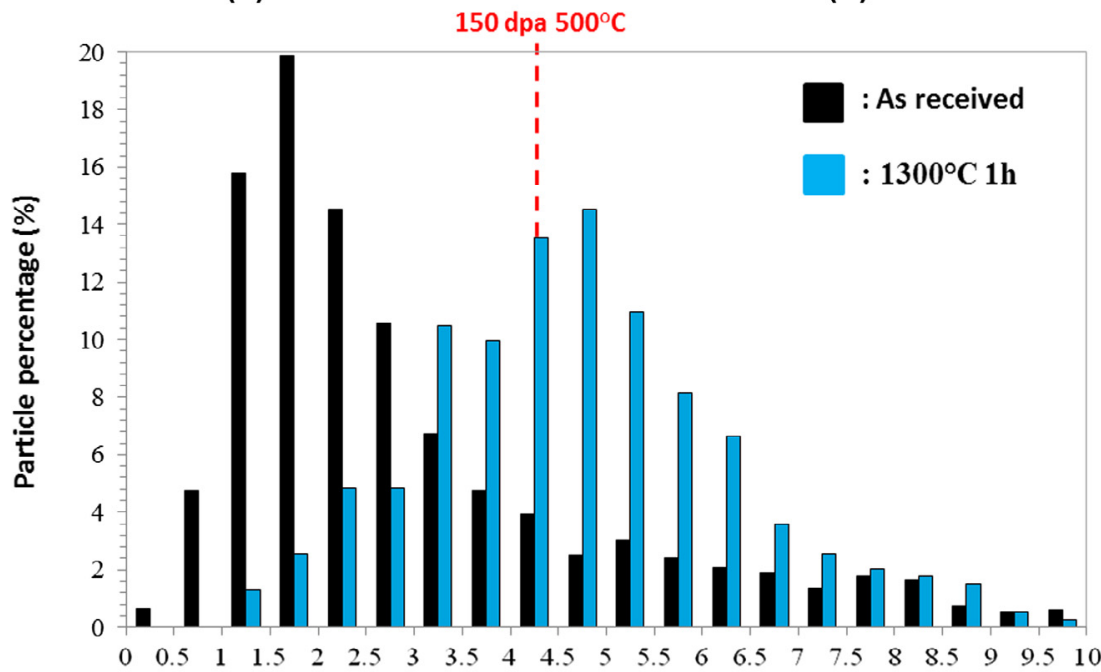

(c)

Equivalent diameter $(\mathrm{nm})$

Fig. 10. Evolution of the nanoparticle distribution after heat treatment: (a) nanoparticle distribution prior to heat treatment; (b) nanoparticle distribution after annealing at $1300^{\circ} \mathrm{C}$ for $1 \mathrm{~h}$; (c) histogram of the distribution prior to and after heat treatment.

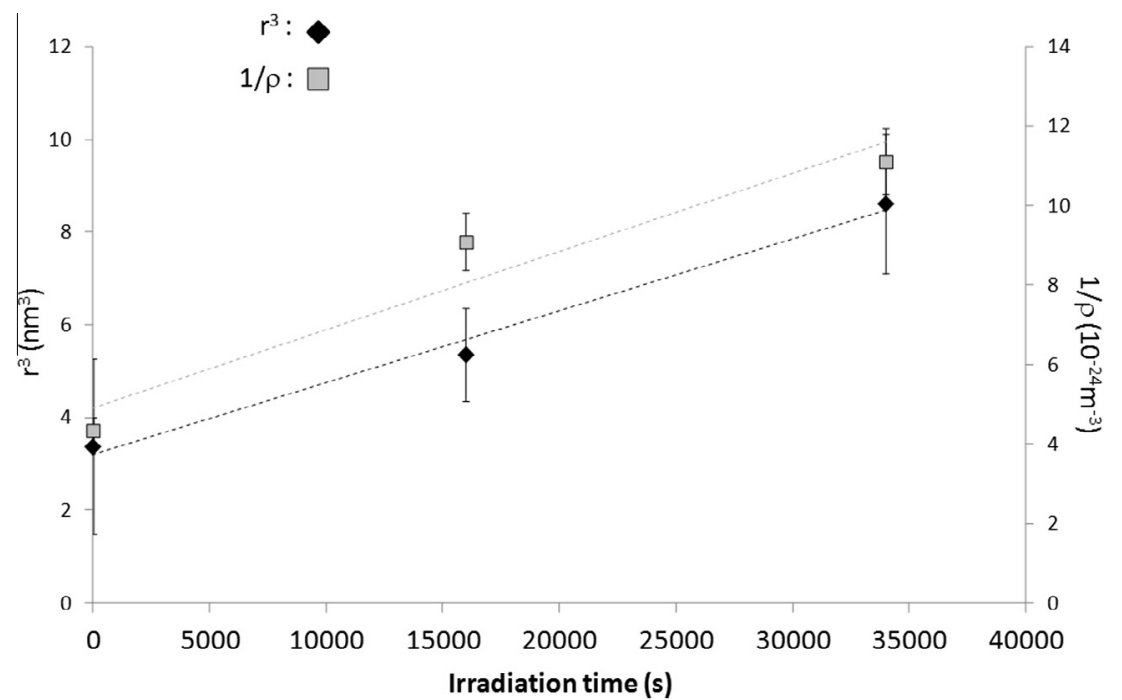

Fig. 11. Plot of the nanoparticle radius raised to the power 3 and of the inverse of the nanoparticle density vs. irradiation time. 


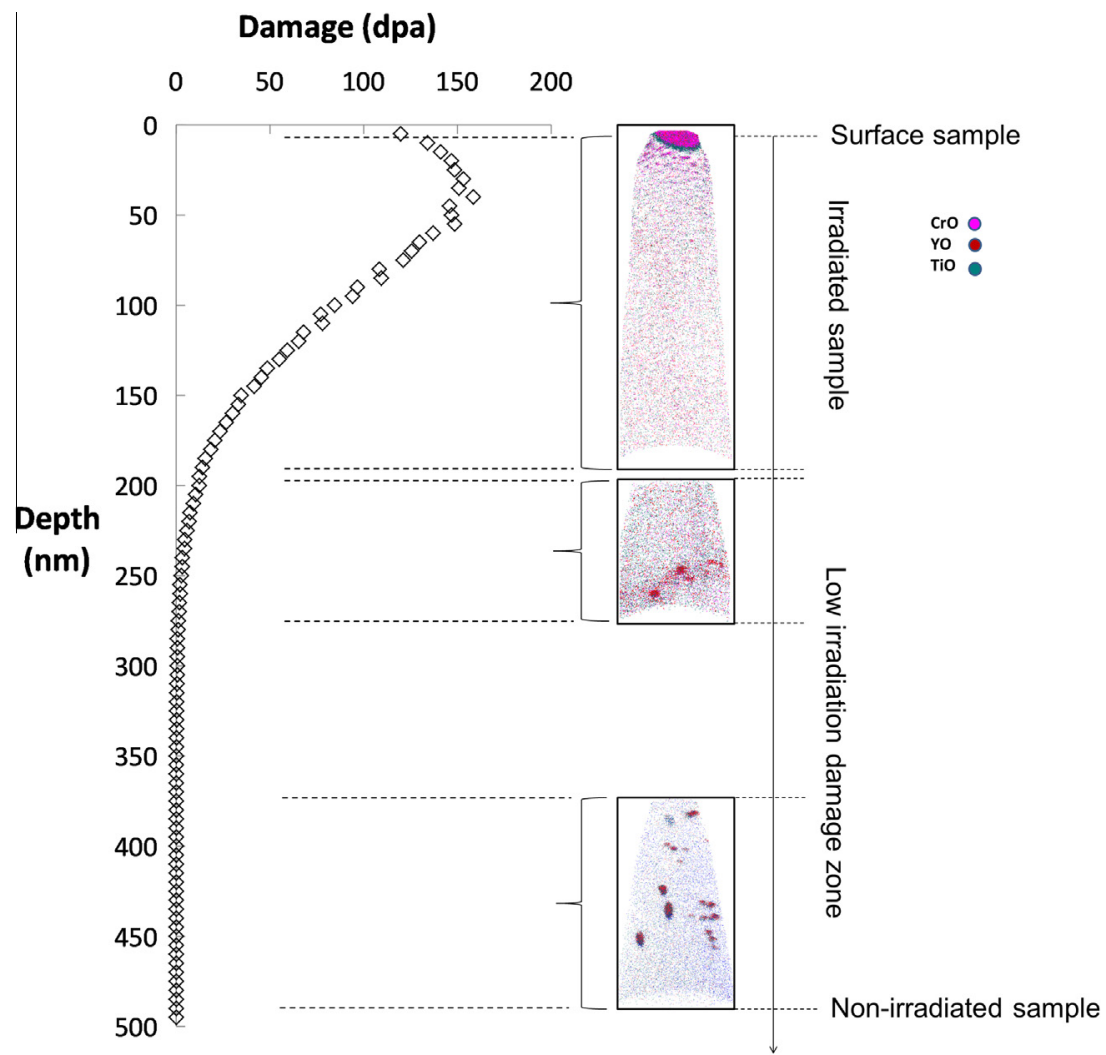

Fig. 12. 3-D APT reconstructions showing the dissolution of $\mathrm{Y}-\mathrm{Cr}-\mathrm{Ti}-\mathrm{O}$ nano-particles being spatially correlated with the depth of Au damage depth profile at room temperature.

coefficient $\mathrm{D}^{\mathrm{B}}$ (Eq. (6)). For $\bar{x}$ in Eq. (6) ranging from 0.2 to $0.5 \mathrm{~nm}$ as estimated using TRIM, $\mathrm{D}^{\mathrm{B}}$ varies between $8.6 \times 10^{-20} \mathrm{~cm}^{2} \mathrm{~s}^{-1}$ and $5.4 \times 10^{-19} \mathrm{~cm}^{2} \mathrm{~s}^{-1}$, which means that $\mathrm{D}^{\mathrm{B}} \gg \mathrm{D}^{\mathrm{Irr}}$ and that the disorder introduced by irradiation prevails over the accelerated thermal diffusion, leading to the observed dissolution of the particles.

\section{Conclusion}

In this study, we demonstrated that nanoparticles of the $\mathrm{Fe} 18 \mathrm{Cr}-\mathrm{Y}_{2} \mathrm{O}_{3}$ ODS alloy with sizes $>2 \mathrm{~nm}$ have a pyrochlore-type structure with a non-stochiometric composition containing $\mathrm{Y}, \mathrm{Ti}, \mathrm{Cr}$ and $\mathrm{O}$. We clearly demonstrated that after high ion dose irradiation $(150 \mathrm{dpa})$ at $500^{\circ} \mathrm{C}$, the nanoparticle distribution exhibited only slight changes in size and composition, resulting in a decrease in the number density and an increase in the nanoparticle size, which is interpreted as an Ostwald ripening process under irradiation. In addition, the particle stoichiometry evolved toward the $\mathrm{Y}_{2} \mathrm{Ti}_{2} \mathrm{O}_{7}$ equilibrium composition with rejection of $\mathrm{Cr}$.

\section{Acknowledgments}

This study was made in the frame of a tripartite agreement between the CEA, AREVA NP and EDF. Irradiations at SRMP-JANNuS Saclay and CSNSM-JANNuS Orsay were performed thanks to the funding of the EMIR network. M.-L.L. acknowledges J.-L. Béchade and M. Le
Flem for scientific support of the study. Y.C. and E.M. acknowledge the University of Michigan College of Engineering for financial support and the ATR NSUF for instrument access at the Center for Advanced Energy Studies (CAES).

\section{References}

[1] de Carlan Y, Béchade JL, Dubuisson P, Séran JL, Billot P, Bougault A, et al. J Nucl Mater 2009;386-388:430.

[2] Yvon P, Carré F. J Nucl Mater 2009;385:217.

[3] Dubuisson P, de Carlan Y, Garat V, Blat M. J Nucl Mater 2012;428:6

[4] Yamashita S, Akasak N, Ukai S, Ohnuki S. J Nucl Mater 2007;367370:202.

[5] Gelles DS. Fusion reactor materials semi annual progress report for the period ending March 31 DOE/ER-0313/16, vol. 21994; 1994. p. 146.

[6] Ribis J. J Nucl Mater 2013;434:178.

[7] Ribis J, Lozano-Perez S. J Nucl Mater 2014;444:314.

[8] Ribis J, Lozano-Perez S. Mater Lett 2012;74:143.

[9] Pareige P, Miller MK, Stoller RE, Hoelzer DT, Cadel E, Radiguet B. J Nucl Mater 2007;360:179.

[10] Yutani K, Kasada R, Kishimoto H, Kimura A. J ASTM Int 2007;4(7):149.

[11] Kimura A, Cho HS, Toda N, Kasada R, Yutani K, Kisimoto H, et al. J Nucl Sci Technol 2007:44:323.

[12] Kishimoto H, Kasada R, Hashitomi O, Kimura A. J Nucl Mater 2009;386-388:533.

[13] Kishimoto H, Yutani K, Kasada R, Hashitomi O, Kimura A. J Nucl Mater 2007:367-370:179. 
[14] Certain AG, Field KG, Allen TR, Miller MK, Bentley J, Busby JT. J Nucl Mater 2010;407:2.

[15] Monnet I, Dubuisson P, Serruys Y, Ruault MO, Kaïtasov O, Jouffrey B. J Nucl Mater 2004:335:311.

[16] Certain A, Kuchibhatla K, Shutthanandan V, Hoelzer DT, Allen TR. J Nucl Mater 2013;434:311.

[17] Williams CA, Marquis EA, Cerezo A, Smith GDW. J Nucl Mater 2010;400:37.

[18] Lescoat ML, Ribis J, Gentils A, Kaïtasov O, de Carlan Y, Legris A. J Nucl Mater 2012;428:176.

[19] Vaumousse D, Cerezo A, Warren PJ. Ultramicroscopy 2003;95:215.

[20] Cerezo A, Davin L. Surf Interface Anal 2007;39:184.

[21] Pellegrino S, Trocellier P, Miro S, Serruys Y, Bordas E, Martin H, et al. Nucl Instrum Methods Phys Res B 2012;273:213.

[22] Chauvin N, Henry S, Flocard H, Fortuna F, Kaïtasov O, Pariset P, et al. Nucl Instrum Methods Phys Res B 2007;261:34.

[23] Stoller RE, Toloczko MB, Was GS, Certain AG, Dwaraknath SD, Garner FA. Nucl Instrum Methods Phys Res Sec B 2013;310:75.

[24] Ziegler JF, Biersack JP. SRIM-2003 program. Yorktown, NY: IBM Corp.; 2003.

[25] Ribis J, de Carlan Y. Acta Mater 2012;60:238.

[26] Williams CA. Mater Res Soc Symp Proc 2010;1289:328.

[27] Nogiwa K, Nishimura A, Yokoyama A, Ohtsuka S, Kaito T, Inoue M, et al. J Nucl Mater 2011;417:201.

[28] Kim IS, Hunn JD, Hashimoto N, Larson DL, Maziasz PJ, Miyahara K, et al. J Nucl Mater 2000;280:264.
[29] Miller MK, Kenik EA, Russel KF, Heartherly L, Hoelzer DT, Maziasz PJ. Mater Sci Eng A 2003;353:140.

[30] Miller MK, Russel KF, Hoelzer DT. J Nucl Mater 2006;351:261.

[31] Yamashita S, Akasaka N, Ohnuki S. J Nucl Mater 2004;329-333:377.

[32] Wu Y, Haney EM, Cunningham NJ, Odette GR. Acta Mater 2012;60:3456.

[33] Marquis EA. Appl Phys Lett 2008:93:181904.

[34] Lozano-Perez S, de Castro Bernal V, Nicholls RJ. Ultramicroscopy 2009; 109:1217.

[35] Sakasegawa H, Chaffron L, Legendre F, Boulanger L, Cozzika T, Brocq M, et al. J Nucl Mater 2009;384:115.

[36] Sakasegawa H, Legendre F, Boulanger L, Brocq M, Chaffron L, Cozzika T, et al. J Nucl Mater 2011;417:229.

[37] Dawson K, Tatlock GJ. J Nucl Mater 2014;444:252.

[38] Was G. Fundamentals of radiation materials science. Berlin: Springer Verlag; 2007.

[39] Soisson F, Fu CC. Phys Rev B 2007:76:214102.

[40] Hin C, Wirth BD. J Nucl Mater 2010;402:30.

[41] Heinig KH, Müller T, Schmidt B, Strobel M, Möller W. Appl Phys A 2003;77:17.

[42] Lifshitz IM, Slyozov VV. J Phys Chem 1961;19:35; Wagner C. Z Elektrochemie 1961;65:581.

[43] Matteucci F, Cruciani G, Dondi M, Baldi G, Barzanti A. Acta Mater 2007:55:2229.

[44] Bellon P, Martin G. Phys Rev B 1988;38:2570. 